\title{
Impacts of battery characteristics, driver preferences and road network features on travel costs of a plug-in hybrid electric vehicle (PHEV) for long-distance trips
}

\author{
Okan Arslan, Barış Yıldız, Oya Ekin Karaşan* \\ Bilkent University, Department of Industrial Engineering, Bilkent, 06800 Ankara, Turkey
}

H I G H L I G H T S

- We investigate the travel costs of CVs, HEVs and PHEVs for long-distance trips.

- We analyze the impacts of battery, driver and road network characteristics on the costs.

- We provide critical managerial insights to shape the investment decisions about PHEVs.

- Drivers' stopping intolerance may hamper the cost and emission benefits of PHEVs.

- Negative effect of intolerance on cost may be overcome by battery capacity expansion.

\section{A R T I C L E I N F O}

\section{Article history:}

Received 24 February 2014

Received in revised form

5 August 2014

Accepted 13 August 2014

Available online 6 September 2014

\section{Keywords:}

PHEV economics

Fast charging stations

Long-distance travel

Driving patterns

Charging strategies

\begin{abstract}
A B S T R A C T
In a road network with refueling and fast charging stations, the minimum-cost driving path of a plug-in hybrid electric vehicle (PHEV) depends on factors such as location and availability of refueling/fast charging stations, capacity and cost of PHEV batteries, and driver tolerance towards extra mileage or additional stopping. In this paper, our focus is long-distance trips of PHEVs. We analyze the impacts of battery characteristics, often-overlooked driver preferences and road network features on PHEV travel costs for long-distance trips and compare the results with hybrid electric and conventional vehicles. We investigate the significance of these factors and derive critical managerial insights for shaping the future investment decisions about PHEVs and their infrastructure. In particular, our findings suggest that with a certain level of deployment of fast charging stations, well established cost and emission benefits of PHEVs for the short range trips can be extended to long distance. Drivers' stopping intolerance may hamper these benefits; however, increasing battery capacity may help overcome the adverse effects of this intolerance.
\end{abstract}

(c) 2014 Elsevier Ltd. All rights reserved.

\section{Introduction}

Volatile gasoline prices, security concerns associated with oil and increasing environmental consciousness have fostered cheaper and greener transportation through the emergence of several new transportation technologies. One such technology is the hybrid electric vehicle (HEV) that benefits from an electric motor to increase the efficiency and reduce the gasoline usage. Another technology that combines the advantages of electric vehicles (EVs) and conventional vehicles (CVs) is the plug-in hybrid electric vehicle (PHEV). Different

\footnotetext{
*Corresponding author. Tel.: +90 312290 1409; fax: +90 3122664126.

E-mail addresses: okan.arslan@bilkent.edu.tr (O. Arslan), baris.yildiz@bilkent.edu.tr (B. Yıldız), karasan@bilkent.edu.tr (O. Ekin Karaşan).
}

from HEVs, PHEVs can be plugged-in to be recharged. A PHEV can travel using two different energy sources: electricity and gasoline. It has a battery and an electric motor as well as an internal combustion engine. Similar to an EV, it can plug-in to recharge its battery and travel in a charge-depleting (CD) mode. When the state of charge (SoC) reaches a certain minimum level, the vehicle can travel in a charge-sustaining (CS) mode, similar to a $\mathrm{CV}$, using gasoline as the main source of energy. Therefore, a PHEV has the cost and emission benefits of an EV and the range benefit of a CV. This new technology results in several new opportunities, including reduced transportation cost; with increasing gasoline prices, drivers are more drawn to electric-drive transportation. A reduction in gasoline usage is also a benefit for oil-importing governments because it implies less foreign dependency. Using electricity as an energy source also significantly reduces greenhouse gas (GHG) emissions (Ma et al., 2012; Kyle and 
Kim, 2011). In addition, investment opportunities emerge with the introduction of PHEVs into the transportation system; car manufacturers and infrastructure investors alike may benefit from this new technology. New fast charging station facilities are being established to provide more recharging opportunities. The whole transportation sector is undergoing a profound transformation and impacts of PHEV penetration into the transportation system have been the subject of recent research.

\subsection{Literature review}

Several papers deal with PHEV-related subjects, including, but not limited to, range requirement analysis (Pearre et al., 2011; Franke and Krems, 2013), PHEV impacts on the electricity network (Sioshansi and Miller, 2011; Nurre et al., 2014; Arslan and Karaşan, 2013; Galus et al., 2010; Weiller, 2011; Axsen et al., 2011), battery capacity analysis (Albertus et al., 2008; Catenacci et al., 2013; Scrosati and Garche, 2010), environmental impacts (Stephan and Sullivan, 2008; Smith, 2010; Marshall et al., 2013), market analysis (Gardner et al., 2013; Khan and Kockelman, 2012; Axsen and Kurani, 2013; Eppstein et al., 2011) and location optimization of recharging infrastructure (He et al., 2013; Wang and Lin, 2009; MirHassani and Ebrazi, 2012). A summary of recent studies in the literature related to the economics of PHEVs is presented in Table 1 . Several researchers identify driving patterns as a significant factor in PHEV economics and analyze their impacts. In this respect, Neubauer et al. (2013) show that the key parameters affecting PHEV economics are driving patterns. Karabasoglu and Michalek (2013) report that driving conditions have a significant impact on PHEV economics and environmental benefits. Along these lines, another interesting paper is presented by Shiau et al. (2009), who investigate the impacts of charging patterns on PHEV economics. The authors consider PHEV charging frequencies and investigate the results with respect to how often the vehicles must stop in order to charge their batteries. They argue that the best battery capacity choice for PHEVs depends on this charging frequency and PHEV economics depend largely on charging patterns of the driver. In a different paper, Peterson and Michalek (2013) study the cost-effectiveness of PHEV battery capacity and charging infrastructure investment for reducing US gasoline consumption. The authors conclude that increased PHEV battery capacity results in higher gasoline savings than charging infrastructure. For the above models and data, we refer the reader to the respective paper.

Most of the aforementioned papers assume exogenous data corresponding to trips originally traveled by CVs. Some also consider driving data that were actually traveled by a limited number of PHEVs in experimental surveys. They carry out analyses by generalizing these results. Davies and Kurani (2013) report that these assumptions may not reflect the real world and must be cautiously made. This finding has a significant bearing on the point of origin of the current study.

\subsection{Problem definition}

With its electric motor and recharging capability, a PHEV offers unique opportunities to decrease the travel costs and GHG emissions. However, various parameters, such as battery characteristics, availability of recharging stations and driver preferences affect the magnitude of these improvements. Analyzing the effects of these parameters for long-distance trips is the focal point of this study. In this regard, we do not consider the cost of setting up new fast charging stations, but concentrate on the long-distance travel costs of PHEVs that require refueling and/or recharging. Note that inclusion of infrastructure costs might affect the results for the battery switching station case as shown by Neubauer and Pesaran (2013).

Because of the basic differences between PHEVs, HEVs and CVs, trip characteristics of these vehicles can be quite different. For a simple example, consider a PHEV and a CV traveling between the same departure and destination points. Assume that the shortest path between these points has several refueling stations but no fast charging station and there is an alternative path, only a few miles longer than the shortest path with several fast charging stations. Obviously, the CV prefers to travel on the shortest path to minimize travel costs. On the other hand, assuming price advantage of electricity over the gasoline as a source of energy, the PHEV travels on the longer path for much less travel cost than that of $\mathrm{CV}$. Even if PHEV and CV follow the same path, it is possible that PHEV adheres to a different refueling/recharging policy to minimize travel costs. As a result, depending solely on the CV travel data might not be sufficient to derive policy conclusions. In this study, we address this issue by simulating long-distance trips in a transportation network with refueling and fast charging stations for drivers with different stopping and distance tolerances.

Widespread deployment of fast charging stations is being offered as a possible remedy for driver's range anxiety. Some research, including Romm (2006) and Wang and Lin (2009), argue that a limited number of refueling/fast charging stations is a barrier to the proliferation of alternative fuel vehicles. However, a prevalence of fast charging stations might not solely overcome this concern. Because a PHEV may only travel a limited mileage in $\mathrm{CD}$ mode, it requires frequent stops when traveling long distances to remain in $\mathrm{CD}$ mode. The driver, however, might be reluctant to stop so often. Therefore, the tolerance of the driver for stopping, which we refer to as stopping tolerance, is also a key parameter in PHEV travel costs. Similarly, driver's tolerance for longer distances, which we refer to as distance tolerance, is another factor that affects PHEV travel costs. If the driver is intolerant for longer trips, then he/she might not accept to deviate from the shortest path to visit a fast charging station and take advantage of the price

Table 1

Recent literature related to PHEV economics.

\begin{tabular}{|c|c|c|}
\hline Authors & Subject & Driving data source \\
\hline $\begin{array}{l}\text { Özdemir and Hartmann } \\
\text { (2012) }\end{array}$ & Impacts of electricity range and gasoline price levels on the PHEV economics & Mobilität in Deutschland \\
\hline Lunz et al. (2012) & The influence of PHEV charging strategies on charging and battery degradation cost & European Energy Exchange (EEX) \\
\hline Neubauer et al. (2013) & $\begin{array}{l}\text { The impacts of driving pattern, electricity range, energy management and charge } \\
\text { strategies on PHEV economics }\end{array}$ & $\begin{array}{l}\text { The Puget Sound Regional Council's } 2007 \text { Traffic } \\
\text { Choices Study }\end{array}$ \\
\hline $\begin{array}{l}\text { Karabasoglu and } \\
\text { Michalek (2013) }\end{array}$ & PHEV life-cycle cost and emission benefits for varying ranges and driving conditions & 2009 National Household Travel Survey (NHTS) \\
\hline $\begin{array}{l}\text { Peterson and Michalek } \\
\text { (2013) }\end{array}$ & The cost-effectiveness of PHEV battery capacity and charging infrastructure investment & 2009 NHTS \\
\hline Shiau et al. (2009) & The impacts of charging patterns on PHEV economics & Simulations \\
\hline
\end{tabular}


difference. As a result, PHEV travel costs would be adversely affected by the distance intolerance. Therefore, analyzing PHEV travel costs should be viewed wholistically, taking into account battery characteristics as well as driver preferences, and the location and availability of refueling/fast charging stations. Different than the existing literature, we consider the driver and network aspects of the problem when conducting economics analyses and analyze the path that a PHEV may prefer to take, which may be different than that of a CV. We also consider battery degradation in the analyses, which proves to be a significant component of the overall cost of a PHEV trip due to rather limited lifespan of a typical battery. In this context, we analyze longdistance travel costs of PHEVs in terms of real-world dynamics on three groups of independent factors: battery characteristics, driver preferences and road network features. We investigate the interactions of these factors, and rank the contribution of each level of these factors to the total cost. This analysis provides critical managerial insights which are extremely relevant in shaping future investment decisions about PHEVs and their infrastructure. Ultimately, the findings of this paper hold imperative information for policy makers, governments and investors who would like to fully exploit the opportunities offered by the game changing PHEV technology.

\section{Material and methods}

We consider a long-range trip between a departure and a destination point in a road network with refueling and fast charging stations. We use the road network of California as the network instance and model long-distance trips between urban population clusters on this real world example. We utilize the dynamic programming heuristic solution methodology for solving the Minimum Cost Path Problem for PHEV (MCPP-PHEV) as presented by Arslan et al. (2014) to simulate trips for various types of drivers with different stopping and distance tolerances. In the following, we present the basic information related to this methodology and discuss the data and parameter settings pertinent to the analysis.

\subsection{Model}

The details to solve the MCPP-PHEV instances are presented in the Appendix. The objective of the presented model is to determine the minimum-cost path of a PHEV for a given departure and destination pair in a network with refueling and fast charging stations. The inputs are related to the vehicle, road network and driver preferences. The required PHEV data are the minimum limits and capacities of the battery and the gasoline tank, the initial states of the battery charge and gasoline levels, the gasoline consumption per mile in CS mode, the electricity consumption per mile in $\mathrm{CD}$ mode and the battery cost. The road network data includes connectivity of nodes, arc distances, availability of refueling and fast charging stations and the prices of electricity and gasoline at nodes. The discomforts due to each stop and extra mileage are quantified in monetary cost value.

The objective function of the model is the sum of five cost components: gasoline, electricity, battery degradation, stopping and distance costs. Gasoline and electricity costs are due to purchases at stations. A PHEV battery has a limited lifespan, and it deteriorates through usage. Thus, a battery degradation cost is incurred with respect to how much the battery is depleted. Stopping and distance costs represent the tolerance of the driver, and high stopping and distance costs imply low tolerance for additional stopping and extra mileage.

Given the inputs and a specific travel path from departure to destination, the model outputs the minimum-cost policy for the specified PHEV to travel this path, the nodes at which a refueling and/or fast charging stop occurs and how much gasoline is to be refueled and whether a charging is to be made at these stops. Note that the path from departure to destination is not only dependent on PHEV specifications but also on driver preferences and the location and availability of fast charging stations. Such a path is found through a dynamic programming heuristic approximating the state space as detailed in the Appendix.

\subsection{Data}

We compare six different vehicle types: a CV, an HEV and four different PHEVs with all-electric range (AER) of 7, 20, 40 and 60 miles. The data pertaining to the vehicles is depicted in Table 2 . The battery capacities, electricity and gasoline usage data are as obtained by Shiau et al. (2009) using the US Department of Energy PSAT Vehicle Physics Simulator. The data accounts for the decreasing efficiency for additional weight due to battery and its structural support. The AER ranges of 7-60 miles span the current PHEV types that are available in the market at the time of this research, such as Toyota Prius and Chevrolet Volt.

\subsection{Road network features}

For the network instance, we use the California road network shown in Fig. 1 that is obtained from a study by Li et al. (2005) and modified to represent the transportation network of California with 1046 nodes and 3312 arcs.

A refueling station is located at every node in the network, and the gasoline price at any station is assumed to be a random value between a minimum and maximum level. As an experimental factor, we investigate two scenarios:

- In the base case, the minimum and maximum prices for the gasoline are $\$ 3.21$ and $\$ 4.07$, respectively. This is the national average gasoline pricing range for a given day in 2014 (US Energy Information Administration, 2014b).

- For the low gasoline pricing range, the minimum and maximum prices are $\$ 1.61$ and $\$ 2.04$, respectively. These are the figures for November 2008 (US Energy Information Administration, 2014b).

Fast charging stations are located randomly at 0\%, 25\%, 50\%, $75 \%$ and $100 \%$ of the network nodes. We refer to these percentages as 'deployment levels'. Similar to the gasoline prices, we model electricity pricing with two scenarios:

- In the base case, the minimum and maximum prices for the

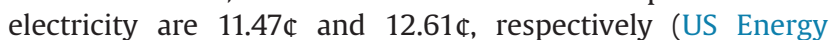
Information Administration, 2014a).

- For the high electricity pricing range, the base case prices are doubled with minimum and maximum prices of $22.94 \mathbb{\complement}$ and $25.22 \Subset$, respectively.

Table 2

Vehicle types and specifications.

\begin{tabular}{lllll}
\hline $\begin{array}{l}\text { Vehicle } \\
\text { type }\end{array}$ & $\begin{array}{l}\text { Tank } \\
\text { capacity } \\
\text { (gal) }\end{array}$ & $\begin{array}{l}\text { Battery } \\
\text { capacity (kWh) }\end{array}$ & $\begin{array}{l}\text { Gasoline usage } \\
\text { (gal/mile) }\end{array}$ & $\begin{array}{l}\text { Electricity usage } \\
(\mathrm{kWh} / \mathrm{mile})\end{array}$ \\
\hline CV & 11.9 & $\mathrm{~N} / \mathrm{A}$ & 0.0353 & $\mathrm{~N} / \mathrm{A}$ \\
HEV & 11.9 & $\mathrm{~N} / \mathrm{A}$ & 0.0193 & $\mathrm{~N} / \mathrm{A}$ \\
PHEV7 & 10.6 & 3.0 & 0.0194 & 0.179 \\
PHEV20 & 10.6 & 8.2 & 0.02 & 0.183 \\
PHEV40 & 10.6 & 16.8 & 0.0204 & 0.188 \\
PHEV60 & 10.6 & 26.4 & 0.0209 & 0.197 \\
\hline
\end{tabular}




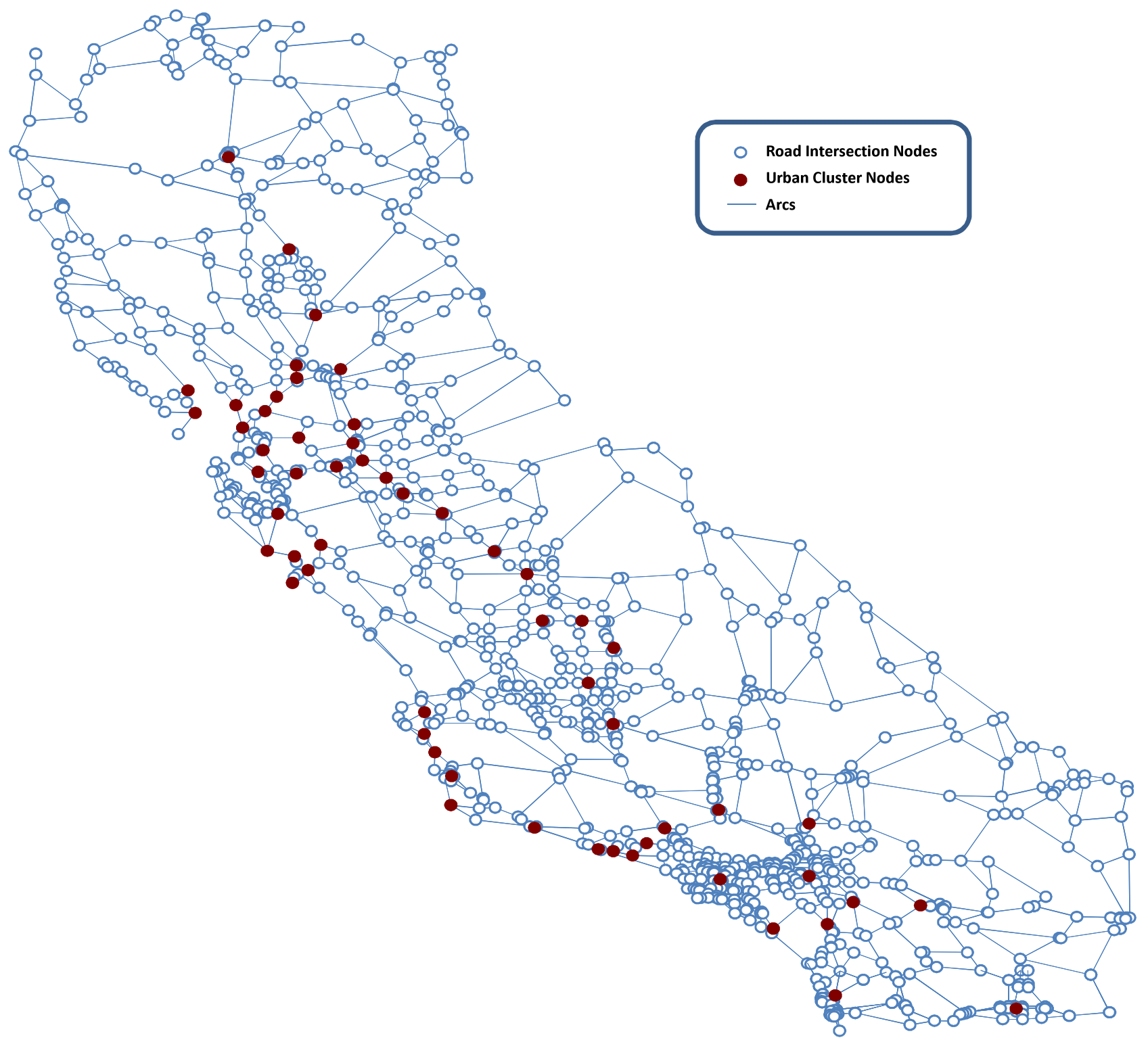

Fig. 1. California road data with 1046 nodes and 3312 arcs.

There are 57 urban clusters in California with 50,000 or more population count (US Census Bureau, 2010) as shown in Fig. 1. 1345 of the 1596 possible origin-destination pairs between these 57 urban clusters are 60 or more miles apart from each other. For our analyses, we randomly choose 30 trips and simulate each trip with all 6 vehicle types considered in this study. The total travel distance distribution is depicted in Fig. 2.

\subsection{Driver preferences}

A PHEV driver is characterized with two parameters: stopping tolerance and distance tolerance. Stopping tolerance represents the monetary value for the inconvenience of refueling/recharging stops. Thus, a lower stopping tolerance value implies a higher tolerance for stopping and vice versa. In our simulations, we study stopping tolerance values between $0 ₫$ and 500®. The rationale behind these levels is as follows: consider a PHEV60 that requires the least number of stops among PHEVs considered in this study. PHEV60 can travel 507 miles on CS mode with only one refueling stop. On the other hand, the same vehicle needs to stop 9 times in order to travel the same mileage on CD mode. The travel cost of CS

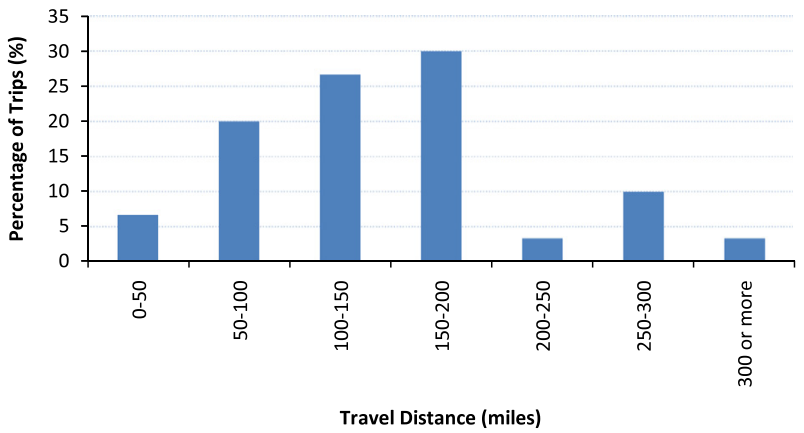

Fig. 2. Travel distance distribution.

mode trip is at most $4314 \llbracket$ when the gasoline price is assumed to be $\$ 4.07$ (highest possible value) in all refueling stations. Similarly, the travel cost of CD mode trip is at least 1146థ. Thus, when the stopping cost is above 3964, it is never profitable to drive on CD mode because the sum of the 9 stopping tolerance values and the cost of electricity exceeds the sum of the gasoline cost and one 
stopping tolerance value. This limiting value for stopping tolerance

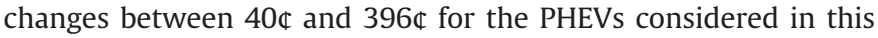
study. Note that stopping tolerance is a measure of the inconvenience to the driver. Thus it can even be zero for some drivers. But when it is above 3964 , gasoline is always preferable, and CS mode drive is always cheaper than CD mode drive. In order to take into account drivers' varying tolerances towards stopping, we consider a wide range of $0 \llbracket$ (high tolerance) to $500 \llbracket$ (low tolerance) values with increments of $100 \uparrow$ in our experimental design. Note that the tolerance levels in parentheses and the tolerance values have an inverse relation. Assuming a refueling or recharging time of 1040 min (Tesla Motors, 2014), 0-500๔ stopping cost value translates to an inconvenience cost of $\$ 0-\$ 30$ per hour.

The second parameter is the distance tolerance which is the monetary value of the inconvenience due to each mile traveled. Lower distance tolerance value implies a higher tolerance for longer trips. We consider a wide range from $0 \mathbb{\uparrow}$ to $50 \llbracket$ distance tolerance values in our experimental design. For an average speed of 60 miles per hour, this translates to an inconvenience cost of $\$ 0-\$ 30$ for an hour of driving. Note that when the distance tolerance is above a certain level, the cost of deviating from the shortest path gets so high that vehicles never detour from the shortest path.

\subsection{Battery characteristics}

Battery capacity is an implicit experimental factor in our study. For the PHEV types considered in this study, battery capacities are 3.0, 8.2, 16.8 and $26.4 \mathrm{kWh}$ as shown in Table 2. The battery cost is also an experimental factor. The battery costs in 2012 are around $\$ 500$ per $\mathrm{kWh}$ and the Department of Energy set battery cost targets of $\$ 300$ per kWh in 2015 and $\$ 125$ per kWh by 2022 for its sponsored research program (Khan and Kushler, 2013). For this reason, we consider $\$ 125 / \mathrm{kWh}, \$ 300 / \mathrm{kWh}$ and $\$ 500 / \mathrm{kWh}$ in the experiments.

A PHEV battery has a limited lifespan, and its life shortens at each cycle. It deteriorates through usage and incurs a battery degradation cost for each battery charge/discharge cycle. Even though it is an implicit cost, the vehicle owner still needs to bear this cost when replacing his/her battery or when buying/selling the vehicle. We assume that the costs are calculated by smart navigation devices that are widely available for drivers. Hence, the algorithms embedded in the devices take into account these implicit costs and save the battery life. This, in turn, minimizes the cost that a driver has to bear. In our study, we assume that a PHEV owner incurs a battery degradation cost depending on the DoD level upon arrival at a fast charging station. According to theoretical studies, the number of cycles is a nonlinear function of depth of discharge (DoD) (Electric Power Research Institute, 2005; Millner, 2010; Sioshansi and Denholm, 2010). We can determine this cost by evaluating a quadratic function of DoD which depends on the battery cost. A sample cost function for a PHEV40 vehicle with $\$ 300 / \mathrm{kWh}$ battery pricing is depicted in Fig. 3 . The DoD is relative to the usable capacity. Thus, a DoD value of 1 implies that the battery is completely depleted, and a value of 0 implies that the battery is at the highest level of its usable capacity. The quadratic cost function is $c_{\delta}^{\text {bat }}=151.23 \times \delta^{2}+71.995 \times \delta$ where $\delta$ is DoD and $c_{\delta}^{\text {bat }}$ is the battery degradation cost. On the other hand, Peterson et al., 2010 report that the real world data shows a linear change of battery life for different DoDs as depicted in the same figure. Linear cost function is $c_{\delta}^{b a t}=219.13 \times \delta$. In this study, we investigated the results for both linear and quadratic modeling techniques.

\subsection{Experimental design}

We define a travel simulation as a trip between an origindestination pair for a specific vehicle type, battery cost, battery modeling technique, stopping and distance tolerance levels, gasoline and electricity pricing levels and fast charging station deployment level in the road network. 30 origin-destination pairs, 6 vehicle types, 5 deployment levels, 3 battery costs, 2 battery modeling techniques, 6 stopping tolerance levels, 5 distance tolerance levels, 2 gasoline pricing levels and 2 electricity pricing levels are considered in this study. In total, there are eight factors with different levels in the experiments (as depicted in Table 3), and the total number of trips that are simulated in our experiments is 648,000 .

Base case for battery cost is assumed to be $\$ 300 / \mathrm{kWh}$. For the tolerance values, we assume that the base case values are zero in order to observe the effects more clearly. With a similar reasoning the base case for the deployment level is assumed to be $100 \%$. We conducted all the simulation runs on a $4 \times 16 \mathrm{C}$ AMD opteron with 96 GB RAM. IBM ILOG CPLEX Optimization Studio 12.4 was used to solve the models. We present the data and the results in the following section.

\subsection{Cost metrics}

The objective function of the MCPP-PHEV model includes electricity cost, gasoline cost, battery degradation cost, distance tolerance cost and stopping tolerance cost. Observe that the tolerances are parameters to model driver preferences and they do not correspond to an actual cost. For this reason, when comparing a PHEV with an HEV or a CV, we need to compare the actual cost of travel, which excludes the tolerance costs. Hence, we use the cost of electricity, gasoline and battery degradation as cost components for comparison. Furthermore, we use distancenormalized cost values to compare trips with different lengths. Consequently, we refer to the sum of electricity, gasoline and battery degradation cost components per mile as the 'levelized cost per mile' (LCPM) (Neubauer and Pesaran, 2011). We define LCPM as

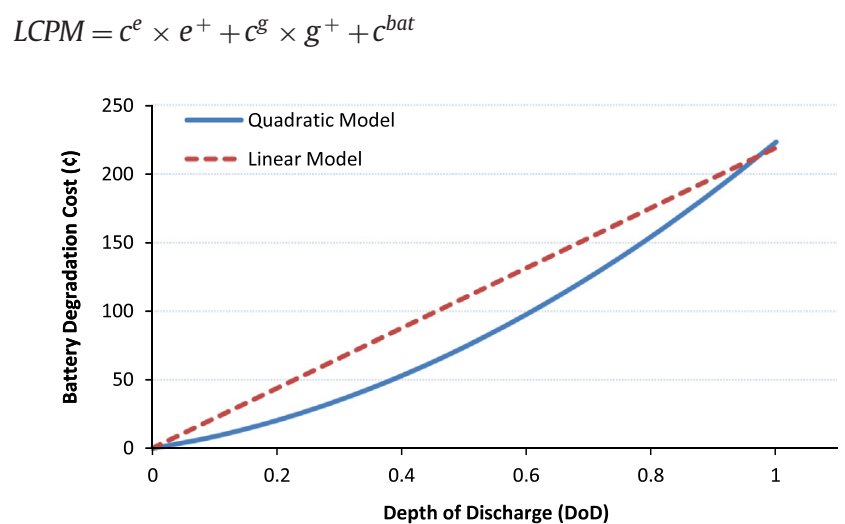

Fig. 3. Quadratic and linear battery degradation cost functions for different DoD values.

Table 3

Experimental factors and their levels to measure the impacts on PHEV travel costs

\begin{tabular}{ll}
\hline Experimental factor & Factor levels \\
\hline Vehicle types & $\{$ CV, HEV, PHEV7, PHEV20, PHEV40, PHEV60 \\
Battery cost $(\$ / \mathrm{kWh})$ & $\{125,300,500\}$ \\
Stopping tolerance $(\mathbb{C})$ & $\{0,100,200,300,400,500\}$ \\
Distance tolerance $(\mathbb{})$ & $\{0,5,10,20,50\}$ \\
Deployment level $(\%)$ & $\{0,25,50,75,100\}$ \\
Gasoline prices $(\$)$ & $\{(1.61-2.04)($ low $),(3.21-4.07)($ high $)\}$ \\
Electricity prices $(\mathbb{})$ & $\{(11.47-12.61)($ low $),(22.94-25.22)($ high $)\}$ \\
Battery degradation modeling & $\{$ linear, quadratic $\}$ \\
\hline
\end{tabular}


where $c^{e}$ is the electricity pricing $(\mathbb{c} / \mathrm{kWh}), e^{+}$is the electricity purchase $(\mathrm{kWh}), c^{g}$ is the gasoline pricing ( $\left.\mathbb{C} / \mathrm{gal}\right), \mathrm{g}^{+}$is the gasoline purchase (gal) and $c^{b a t}$ is the degradation cost of the PHEV battery corresponding to the electricity load of $e^{+}$.

\section{Results and discussion}

In this section, we present the results with respect to two metrics: distance and LCPM. Initially, we study the driver's path preferences, that is, the driving patterns, and analyze differences with respect to the shortest path. Secondly, we investigate the impacts of factors affecting the LCPM individually and carry out an in-depth analysis on the factors that are identified as significant. Lastly, we put forward the relative impacts of each level of the experimental factors and provide strategic managerial insights.

\subsection{Driving pattern analysis}

If refueling and/or charging is not considered in a trip, then the shortest path between two points is the minimum-cost path for a vehicle. However, the driver has the opportunity to reduce travel costs by refueling and/or charging at stations off the shortest path. Out of the 648,000 travel simulations carried out in our experiments, $2.49 \%$ of drivers prefer traveling on paths that were not the shortest. The average deviation from the shortest paths is $2.4 \%$. The extra distance traveled depends on driver preferences and network features.

As shown in Table 4, the deviation from the shortest path for a $\mathrm{CV}$ and an HEV is not affected by the deployment level of the fast charging stations. Similarly, the deviation is fixed for all vehicle types when the deployment level is zero, as expected. For PHEVs, however, the deviation is highest when the deployment level reaches $25-50 \%$ since fast charging stations are sparse in the network. Therefore, PHEVs detour from the shortest paths more often to reach those stations in order to travel on cost effective CD mode. Observe that the average deviation from the shortest path decreases by increasing deployment level beyond $50 \%$ because fast charging stations are encountered on the shortest paths more often.

In the experimental results, all the vehicle types follow the shortest path regardless of the deployment level when the stopping tolerance is above 200๔. A recent study by Perk et al. (2011) reports that the value of travel time might get well above the range of the tolerance values considered in this study. But, increasing the stopping tolerance above $200 \mathbb{c}$ only implies that the vehicles will follow the shortest path and the LCPM values will stay the same.

Even though the deviation changes with respect to different deployment levels, the average deviation from the shortest paths is not significant. This is due to the fact that longer trips require more fuel and/or electricity consumption. Since the travel cost is minimized, the detour from the shortest paths is not a high percentage of the total travel distance.

Table 4

Average deviation from the shortest paths versus deployment level for different stopping tolerances.

\begin{tabular}{lccccc}
\hline Vehicle type & $0 \%$ & $25 \%$ & $50 \%$ & $75 \%$ & $100 \%$ \\
\hline CV & 2.02 & 2.02 & 2.02 & 2.02 & 2.02 \\
HEV & 2.02 & 2.02 & 2.02 & 2.02 & 2.02 \\
PHEV7 & 2.02 & 3.32 & 2.37 & 1.98 & 1.45 \\
PHEV20 & 2.02 & 2.48 & 1.49 & 1.23 & 1.12 \\
PHEV40 & 2.02 & 2.81 & 2.15 & 1.63 & 1.15 \\
PHEV60 & 2.02 & 2.48 & 4.04 & 0.51 & 0.32 \\
\hline
\end{tabular}

\subsection{Levelized cost per mile (LCPM) component breakdown}

Fig. 4 plots LCPM for different fast charging station deployment levels. The LCPM of CV is $11.93 \uparrow$ (not shown in the graph), and it does not change by deployment level since a CV travels solely on gasoline. When there are no fast charging stations in the network (i.e. zero deployment level), the LCPM values of PHEVs are higher than those of an HEV. The reason is the decreased fuel efficiency of PHEVs due to heavier weights. After the initial deployment of fast charging stations, PHEVs start to benefit from CD mode travel and there is a gradual decrease of LCPM with increasing deployment level. The most significant decrease is for PHEV40 among the PHEVs considered in this study. This interesting result shows that after a certain minimum AER is reached, PHEVs with lower battery capacities start to perform better in terms of total travel costs.

Fig. 5 depicts the breakdown of LCPM components for all vehicle types. The LCPM of a CV is 11.93 almost halves the cost with 6.52థ. For the PHEVs, the LCPM gradually decreases with increasing AER, but observe that the decrease in cost is not significant among PHEV types. Again, PHEV40 gives the least cost. Note also that the percentage of the degradation cost is notable among the other cost components.

Fig. 6 plots $C D$ mode travel percentage for PHEVs. Observe that the higher the capacity of the PHEV is, the more the $\mathrm{CD}$ mode drive is. This is the result of increased battery capacity.

\subsection{Effects of experimental factors on LCPM}

The correlation between each experimental factor and the LCPM is used as a way to understand the significance of the impacts on the LCPM. Spearman's Rank Correlation Coefficients (Kutner et al., 2005) between the experimental factors and the LCPM are presented in Fig. 7.

A negative value indicates an inverse relationship. Observe that LCPM decreases by increasing stopping tolerance or deployment level, and by decreasing gasoline prices, battery costs and electricity prices. The distance tolerance has insignificant effect on

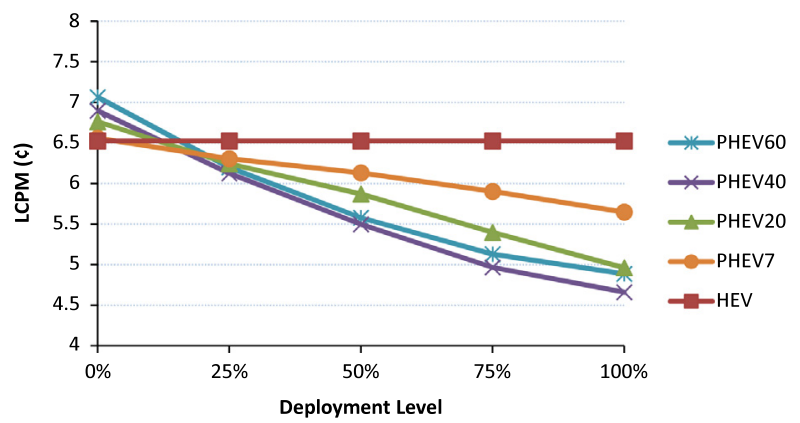

Fig. 4. Levelized cost per mile change with increasing deployment levels.

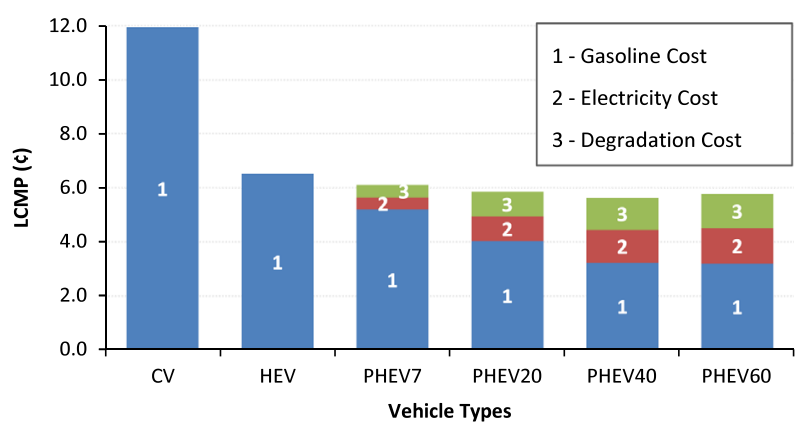

Fig. 5. Breakdown of LCPM components for different vehicle types. 


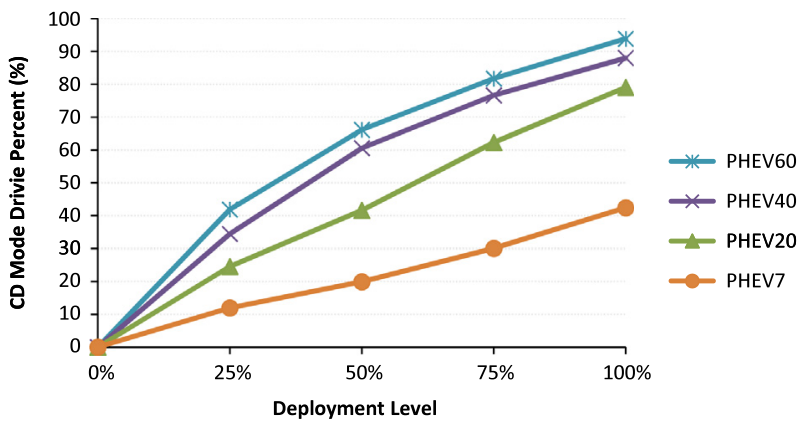

Fig. 6. $C D$ and $C S$ mode drive percentages versus deployment level.

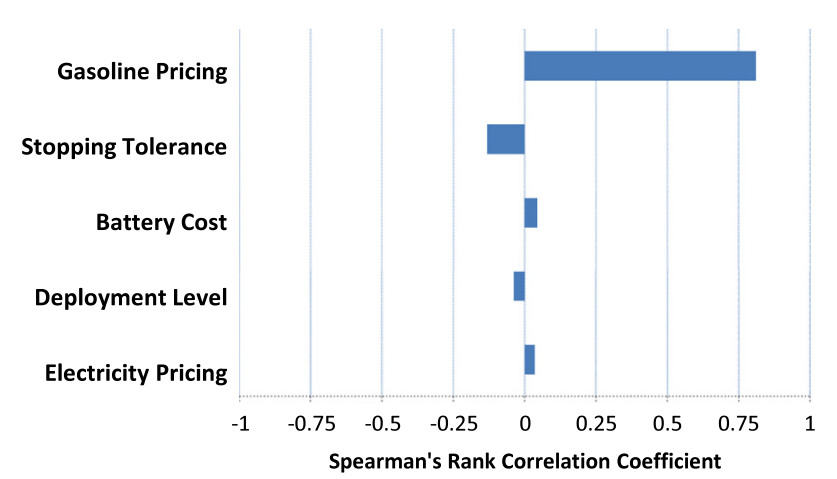

Fig. 7. Spearman's rank correlation coefficients between each experimental factor and LCPM.

LCPM which is due to the fact that the extra mileage requires more gasoline or electricity to be consumed, ultimately increasing the total cost. Increasing the distance tolerance only results in forcing the drivers to follow the shortest paths. As we have observed previously, the total trip distances of a PHEV and CV are very close to each other, and distance tolerance turns out to have an insignificant effect on LCPM.

Another result is that the battery modeling method, whether linear or quadratic, does not affect the results. In other words, the results for each battery model are not statistically different. This is mainly due to limited AER. The PHEV usually depletes the battery fully before recharging again. Thus, the function, whether linear or quadratic, gives a close cost value when evaluated at $\delta=1$ (i.e. when the battery is depleted to minimum SoC).

In the following, we further investigate the factors that have significant correlation with LCPM.

\subsection{Stopping tolerance and deployment level sensitivity}

The impacts of stopping tolerance for the two extreme cases, $0 \%$ and $100 \%$ deployment levels, are depicted in Fig. 8. Each curve in the subfigures corresponds to a different vehicle type. On the horizontal axis, higher stopping tolerance values imply less tolerance for stopping.

Consider 0\% deployment level. Increasing the stopping tolerance value results in increased LCPM, because the drivers make less number of stops to refuel. Note that the vehicles do not benefit from CD mode trip at 0\% deployment level. The LCPM for PHEV60 is the highest when the deployment level is $0 \%$. The decreased efficiency due to additional battery weight is the reason for higher costs. When the deployment level increases to $100 \%$, the LCPM for PHEV60 is the lowest for all stopping tolerance values except zero value. Observe that the LCPM is not changing above a certain tolerance value for all vehicle types for 100\% deployment level.
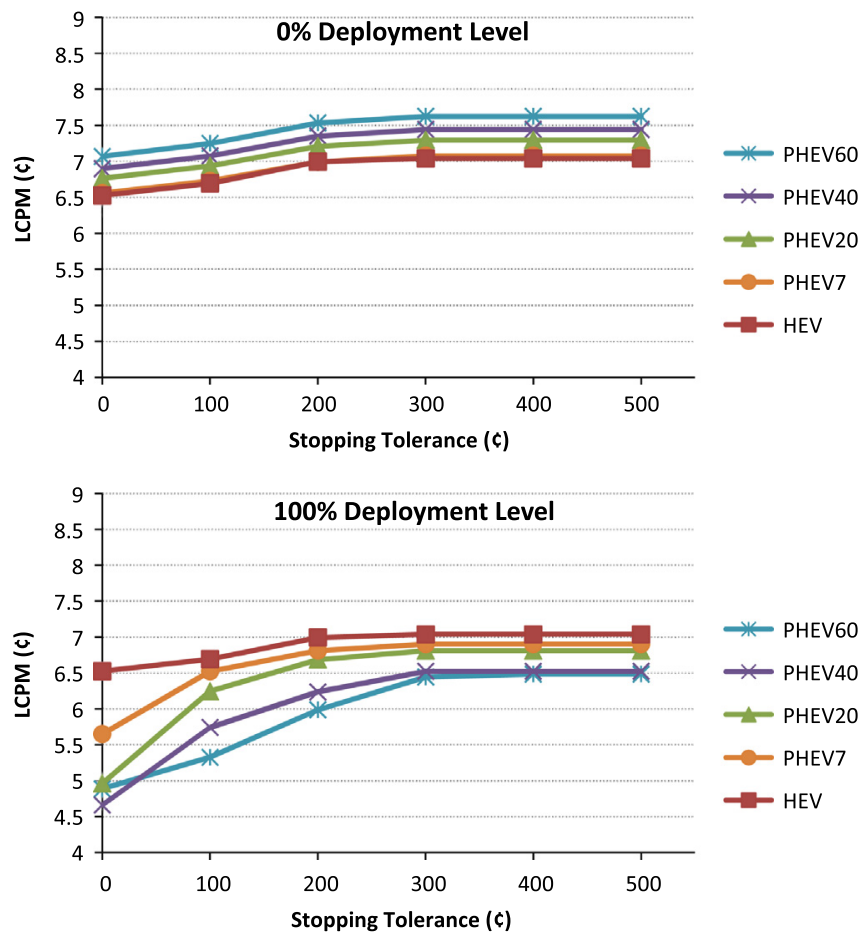

Fig. 8. Stopping tolerance versus LCPM for $0 \%$ and $100 \%$ deployment levels.

This is due to the preference change of the drivers with increasing stopping tolerance value. Thus, there is a critical stopping tolerance at which the driver starts preferring to drive on gasoline rather than electricity; identifying this tolerance correctly is crucial for infrastructure investors. Observe that increasing the deployment level has a positive effect on LCPM, but high stopping tolerance values may hamper this positive impact.

Recall that previously, we had identified PHEV40 as the alternative with the least travel cost for the base case (i.e. when the stopping tolerance value is zero). However, we observe now that PHEV40 is the best alternative for long-distance travels for highly tolerant vehicle drivers. If the driver's intolerance is above zero level, then PHEV60 turns out to be the best alternative from the cost minimization perspective. This is an important result showing that stopping tolerance is a key factor in long-distance travel costs.

Also note that the critical stopping tolerance value is higher for high capacity PHEVs. PHEV7 has a fixed LCPM above 200₫stopping tolerance values, however the critical value is 300๔ for PHEV60. This implies that the higher the mileage that a PHEV can travel nonstop with its fully charged battery, the less the adverse affect of driver stopping intolerance.

\subsection{Electricity and gasoline price sensitivity}

LCPM values for different electricity and gasoline price settings are given in Table 5. The low and high price settings for electricity

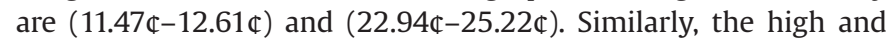
low settings for gasoline are (\$3.21-\$4.07) and (\$1.61-\$2.04), respectively.

Observe that for the low gasoline price setting, i.e. the (low and low) and (high and low) columns in Table 5, the LCPMs are the same for both low and high electricity price settings. This clearly indicates that when the gasoline prices are low enough, it is always preferable for the drivers to travel using gasoline rather than electricity in order to minimize the costs. Similar results are also obtained in the literature (Shiau et al., 2009). When the gasoline price setting is high, PHEV7 performs the best when the 
Table 5

Levelized cost per mile for different price settings.

\begin{tabular}{lllll}
\hline \multirow{2}{*}{$\begin{array}{l}\text { Vehicle } \\
\text { type }\end{array}$} & \multicolumn{3}{l}{ (Electricity and gasoline) prices } \\
\cline { 2 - 5 } & (Low and low) & (High and low) & (Low and high) & (High and high) \\
\hline CV & 5.98 & 5.98 & 11.93 & 11.93 \\
HEV & 3.27 & 3.27 & 6.52 & 6.52 \\
PHEV7 & 3.29 & 3.29 & 5.65 & 6.45 \\
PHEV20 & 3.39 & 3.39 & 4.96 & 6.49 \\
PHEV40 & 3.46 & 3.46 & 4.66 & 6.57 \\
PHEV60 & 3.54 & 3.54 & 4.89 & 6.85 \\
\hline
\end{tabular}

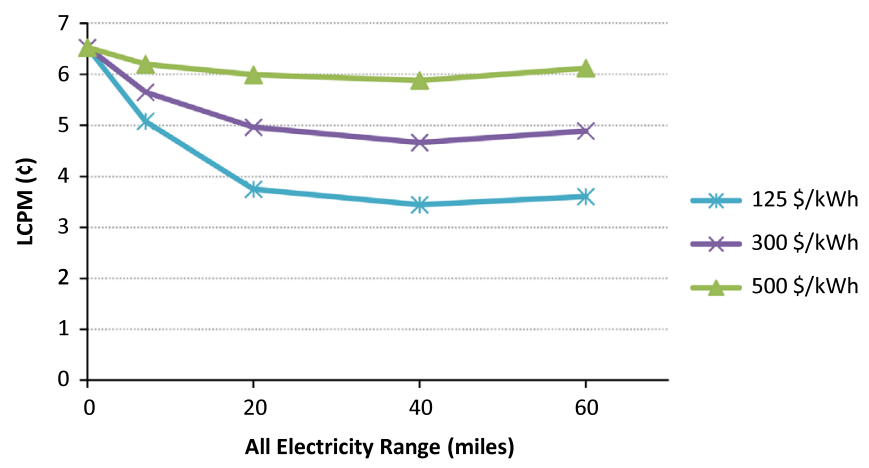

Fig. 9. Battery cost impacts on LCPM.

electricity price is also high. When electricity price is low, larger capacity PHEVs incur less cost and PHEV40 performs the best.

\subsection{Battery cost impacts on LCPM}

Each curve in Fig. 9 represents a different battery cost. Note that zero AER vehicle is HEV, and the other data points in the figure represent PHEVs with the respective AER.

Observe that all curves follow a similar trend. When the AER increases from 0 to 20 miles, the LCPM reduces more steeply than when AER increases from 20 to 60 miles. Increasing the AER from 20 to 60 miles has little effect on levelized cost regardless of battery cost. Again, PHEV40 performs the best for different battery costs.

\subsection{Environmental impacts}

One of the major benefits of PHEVs is their lower GHG emissions compared to CVs. In this section, we analyze the impacts of deployment level of fast charging stations on GHG emissions. In this study, we assume $11.34 \mathrm{~kg}$ of carbon dioxide equivalent $\left(\mathrm{CO}_{2} \mathrm{e}\right)$ emission per gallon of gasoline and $0.730 \mathrm{~kg}$ of $\mathrm{CO}_{2} \mathrm{e}$ emission per kWh of electricity charge (Shiau et al., 2009). For the gasoline emission data, combustion and supply chain emissions are taken into account. For the electricity emission data, generation at the power plant, transmission and distribution losses are considered. The included GHG emissions are for vehicle operation. We do not consider the emissions due to producing the batteries in this study. Fig. 10 plots the total $\mathrm{CO}_{2} \mathrm{e}$ emission of vehicle types per mile in grams for different deployment levels. A CV produces $40 \mathrm{~g}$ of $\mathrm{CO}_{2} \mathrm{e}$ per mile of travel. On the other hand, the other vehicle types produce at most $23.7 \mathrm{~g}$ of $\mathrm{CO}_{2} \mathrm{e}$ per mile, mainly due to increased efficiency. Deployment level also causes a decrease in emission per mile due to $C D$ mode travel increase.

Note that in Table 5, the electricity pricing does not have a significant impact on the LCPM values. Similarly, the emissions are not affected significantly by the electricity prices. However, gasoline pricing has a significant effect on the emissions. Fig. 11

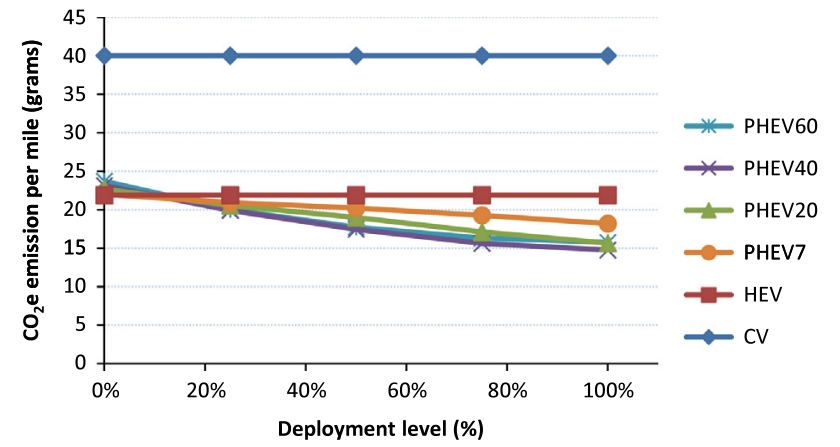

Fig. 10. $\mathrm{CO}_{2} \mathrm{e}$ emissions per mile for vehicle types and different deployment levels.

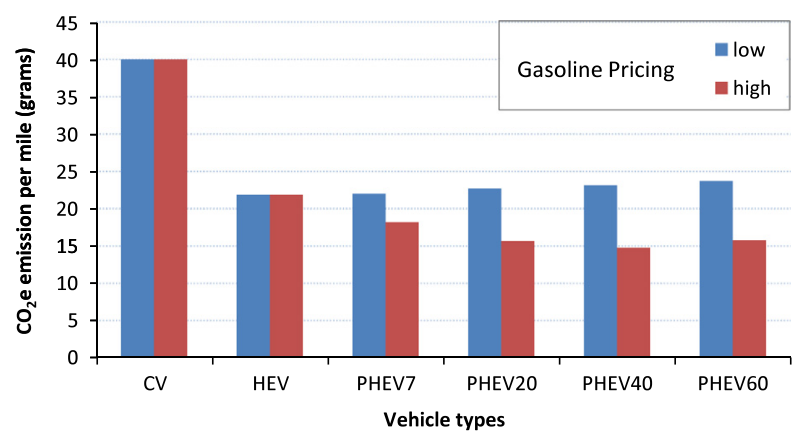

Fig. 11. $\mathrm{CO}_{2} \mathrm{e}$ emissions per mile for vehicle types and gasoline price settings.

plots the $\mathrm{CO}_{2} \mathrm{e}$ emissions for low and high gasoline price settings. When the gasoline prices are high, the drivers prefer to drive more on $C D$ mode and the emission decreases in the range of $17-36 \%$ for the PHEVs.

\subsection{Discussion}

The results of our extensive simulations provide critical insights into travel costs of PHEVs in long-distance trips. First of all, results show that driving patterns are affected by the driver preferences and the network features. The path difference between a CV, an HEV and a PHEV is the largest when the deployment level is between 25 and $50 \%$.

Results also show a gradual decrease of LCPM with increasing deployment level. This is an intuitive result since cost benefit of a PHEV is mainly due to the $C D$ mode travel and high figures for the deployment level enable more CD mode travel for all PHEVs with different AERs. We also observe that the deployment level of fast charging stations needed for a PHEV to be a better alternative than an HEV in terms of long-distance travel costs is between $0 \%$ and $25 \%$.

The battery degradation cost proves to be a significant contributer of the LCPM, especially for the PHEVs with longer AER. Numerical experiments also show that there is not a significant difference between the quadratic and linear battery models investigated in this study.

One of the major findings of this study is the strong connection between the stopping tolerance of the driver and the LCPM of a PHEV trip. Stopping intolerance hampers the benefits of PHEVs even for high deployment levels of fast charging stations. However, higher AER is effective to alleviate the adverse effects of low stopping tolerance. Results also show that there is a critical stopping tolerance at which drivers start driving on gasoline rather than electricity, and identifying this tolerance is crucial to make better infrastructure investment decisions. On the other hand, distance tolerance does not play such an important role in long-distance travel costs. Finally, note that the impact of both stopping tolerance and distance tolerance might be related to each other by value of time. 
In this research, the results are obtained under some mild assumptions about the road networks. We assume that fast charging stations are randomly dispersed in the road network. This is a future research direction and location models can be combined together with models used in this study to arrive at more accurate results.

\section{Conclusion and policy implications}

The benefits of PHEVs for short trips are often touted, but their potential benefits for long distance trips have not attracted much attention. The United States Department of Transportation (2010) reports that in 2009, more than 575 billion vehicle miles were traveled in trips of 50 miles and over, by personally owned vehicles. If only $10 \%$ of these vehicles were PHEVs and only an average cost reduction of $2.5 \mathbb{\leftarrow}$ per mile were achieved, 1.44 billion dollars could be saved annually.

This paper highlights the importance of charging infrastructure on the travel costs of a PHEV for long-distance trips and reveals several important factors, especially driver stopping tolerance and AER. In this regard, the deployment level of charging stations should further be pinpointed for better input to policy decisions. Furthermore, the importance of consumers' stopping tolerance is another policy takeaway; identifying the drivers' actual willingness to stop is an important factor to determine the real world impacts of PHEVs for long distance driving.

In this context, we analyze the impacts of battery characteristics, driver preferences and road network features on PHEV longdistance-travel costs. The existing literature usually assumes exogenous driving profiles and builds models on this strong assumption. However, a PHEV is different from a CV and it might follow different paths between the same departure and destination points in order to reduce its travel costs. The travel cost of a PHEV is affected by factors such as location and availability of refueling/fast charging stations, capacity and cost of PHEV batteries and driver tolerance for extra mileage and additional stopping. If infrastructure is not set up to offer a widespread network of battery charging opportunities, or managerial decisions are made without taking into consideration driver preferences, then drivers' cost reduction expectations might not be satisfied. In this research, we analyze the relative importance of the above factors on PHEV travel costs for long-distance trips by investigating the actual path and refueling/ fast charging locations that a PHEV may prefer, which may be different from those of a CV or an HEV. Furthermore, we study the environmental impacts of these factors.

Analyses show that the price of gasoline is the most important factor affecting the long-distance costs of PHEVs. The availability of fast charging stations is another important factor. Average transportation cost per mile gradually decreases with increasing fast charging station deployment level in the road network. However, drivers' stopping intolerance might hamper this positive impact. There is a critical stopping tolerance beyond which the drivers prefer not to make frequent stops to reduce transportation costs, but instead prefer to travel using gasoline. Having a larger battery capacity decreases the adverse effects of the stopping intolerance.

The results indicate that after an essential initial setup of fast charging stations in the road network is reached, research must be directed towards battery capacity expansion. This key result is important for managers and infrastructure investors alike.

\section{Acknowledgments}

We are thankful to two anonymous referees for their constructive feedback in leading to the current form of this paper.

\section{Appendix A. Dynamic programming heuristic solution technique for the MCPP-PHEV problem}

In this section, we summarize the solution methodology introduced by Arslan et al. (2014) for the interested readers.

We define the formulation $\operatorname{MCPP}(\mathcal{P})$ for finding the minimum cost refueling/recharging policy for a PHEV traveling on path $\mathcal{P}$. The parameters and variables used in the formulation are:

- Parameters

\begin{tabular}{|c|c|}
\hline$N, A$ & sets of nodes and arcs \\
\hline $\mathcal{P}$ & sets of arcs visited on the path \\
\hline$s, t$ & source and destination nodes \\
\hline$s_{i}^{e}, s_{i}^{g}$ & $\begin{array}{l}1 \text { if there is an electricity or refueling station, respec- } \\
\text { tively, at node } i \text {, and } 0 \text { otherwise }\end{array}$ \\
\hline $\bar{P}, \underline{P}$ & $\begin{array}{l}\text { battery maximum and minimum energy capacities, } \\
\text { respectively }(\mathrm{kWh})\end{array}$ \\
\hline $\bar{G}, \underline{G}$ & maximum and minimum tank capacities, respectively (gal) \\
\hline$P_{s}, \bar{P}_{t}$ & $\begin{array}{l}\text { initial and final energy stored in battery of the PHEV } \\
(\mathrm{kWh}) \text {, respectively }\end{array}$ \\
\hline$G_{s}, G_{t}$ & $\begin{array}{l}\text { initial and final gasoline stored in tank of the PHEV (gal), } \\
\text { respectively }\end{array}$ \\
\hline$c$ & average electricity usage of the PHEV (kWh/mile) \\
\hline$\rho$ & average gasoline usage of the PHEV (gal/mile) \\
\hline$d_{i j}$ & length of $\operatorname{arc}(i, j)$ (miles) \\
\hline$c_{i}^{e}$ & price of electricity at node $i(\mathbb{\complement} / \mathrm{kWh})$ \\
\hline$c_{1}^{g}$ & price of gasoline at node $i(\mathbb{C} / \mathrm{gal})$ \\
\hline$c^{s t}$ & stopping cost $(\mathbb{C})$ \\
\hline$c^{\text {dep }}$ & iation cost of traveling for a mile \\
\hline
\end{tabular}

\section{- Variables}

$e_{i}^{\alpha}, e_{i}^{\beta} \quad$ charge level at node $i$ at arrival and departure, respectively $(\mathrm{kWh})$

$e_{i}^{+} \quad$ net electric energy change at node $i(\mathrm{kWh})$

$g_{i}^{\alpha}, g_{i}^{\beta} \quad$ gasoline level at node $i$ at arrival and departure, respectively (gal)

$g_{i}^{+} \quad$ gasoline transferred to the PHEV at node $i$ (gal)

$v_{i} \quad 1$ if the PHEV switches battery at node $i$, and 0 otherwise

$r_{i} \quad 1$ if the PHEV refuels and/or switches battery at node $i$, and 0 otherwise

$\delta_{\mathrm{i}} \quad$ depth of discharge (DoD) at node $i$ at arrival

$c^{\text {bat }}\left(\delta_{i}\right)$ degradation cost of the PHEV battery at node $i$

$d_{i j}^{c d}, d_{i j}^{c s}$ travel distance in charge-depleting (CD) and chargesustaining (CS) mode while traveling on arc $(i, j)$, respectively (miles)

The formulation is as follows:

$$
\begin{array}{r}
\operatorname{minimize} \quad \sum_{i \in N} c_{i}^{e} \times e_{i}^{+}+\sum_{i \in N} c_{i}^{g} \times g_{i}^{+}+\sum_{i \in N} c^{\text {bat }} \delta_{i} \\
+\sum_{i, j \in P} d_{\mathrm{ij}} \times c^{\mathrm{dep}}+\sum_{i \in N} c^{\mathrm{st}} \times r_{i}
\end{array}
$$

subject to

$e_{i}^{\beta}=e_{i}^{\alpha}+s_{i}^{e} \times e_{i}^{+} \quad \forall i \in N$

$e_{j}^{\alpha}-e_{i}^{\beta}+\varepsilon \times d_{i j}^{c d}=0 \quad \forall(i, j) \in \mathcal{P}$

$\underline{P} \leq e_{i}^{\alpha} \leq \bar{P} \quad \forall i \in N$

$\underline{P} \leq e_{i}^{\beta} \leq \bar{P} \quad \forall i \in N$

$e_{i}^{+} \leq v_{i} \times \bar{P} \quad \forall i \in N$ 


$$
\begin{aligned}
& e_{i}^{\beta} \geq v_{i} \times \bar{P} \quad \forall i \in N \\
& v_{i} \leq r_{i} \quad \forall i \in N \\
& e_{s}^{\alpha}=P_{s} \\
& e_{t}^{\alpha} \geq P_{t} \\
& \delta_{i}=\frac{e_{i}^{+}}{\bar{P}} \quad \forall i \in N \\
& c^{b a t}\left(\delta_{i}\right) \geq a \times\left(\delta_{i}\right)^{2}+b \times \delta_{i}-M \times\left(1-v_{i}\right) \quad \forall i \in N \\
& g_{i}^{\beta}=g_{i}^{\alpha}+s_{i}^{g} \times g_{i}^{+} \quad \forall i \in N \\
& g_{j}^{\alpha}-g_{i}^{\beta}+\rho \times d_{i j}^{c s}=0 \quad \forall(i, j) \in \mathcal{P} \\
& \underline{G} \leq g_{i}^{\alpha} \leq \bar{G} \quad \forall i \in N \\
& \underline{G} \leq g_{i}^{\beta} \leq \bar{G} \quad \forall i \in N \\
& g_{i}^{+} \leq r_{i} \times \bar{G} \quad \forall i \in N \\
& g_{s}^{\alpha}=G_{s} \\
& g_{t}^{\alpha} \geq G_{t} \\
& d_{i j}^{c s}+d_{i j}^{c d}=d_{i j} \forall(i, j) \in A \\
& v_{k}, r_{k} \in\{0,1\} ; d_{i j}^{c d}, d_{i j}^{c s}, e_{k}^{\alpha}, e_{k}^{\beta}, e_{k}^{+}, g_{k}^{\alpha}, g_{k}^{\beta}, g_{k}^{+}, \delta_{k}^{\alpha}, c_{k}^{b a t} \geq 0 \\
& \forall k \in N, \forall(i, j) \in A
\end{aligned}
$$

In order to present the algorithm succinctly, we first define the minimum cost transition function $f: N \times N \rightarrow \mathbb{R}$ that takes two nodes $i$ and $j$ as its arguments and returns the minimum cost for the transition from node $i$ to node $j$ by starting and ending with $P$ kWh charge and $G$ gallons of gasoline without any refueling and recharging in between. Note that calculation of $f(i, j)$ requires to consider 3 distinct cases:

- refuel but not recharge at node $i$, use only the CS mode and incur the start stop and gasoline cost to cover the distance between $i$ and $j$.

- recharge but not refuel at node $i$ use only CD mode and incur the start stop and recharging cost to cover the distance between $i$ and $j$.

- both refuel and recharge at node $i$, use both CD and CS modes and incur the start stop, recharging and refueling cost.

We say $f(i, j)=\infty$ if the transition is infeasible. For a given network instance $G=(N, A)$, we define the weighted DH-Graph $\tilde{G}:=(N, \tilde{A}, f)$, where $\tilde{A}$ contains an arc $(i, j)$ for each node pair $i, j \in N$ such that $f(i, j)<\infty$. For each $\operatorname{arc}(i, j) \in \tilde{A}$, the weight is given by $f(i, j)$.

With the given notation, the pseudo code for the algorithm is as follows:

Algorithm 1. Dynamic programming heuristic solution technique for the MCPP-PHEV problem.

\section{begin}

Generate DH - Graph $\tilde{G}:=(N, \tilde{A}, f)$

Let $\tilde{\mathcal{P}}$ be the set of $\operatorname{arcs}(i, j) \in \tilde{A}$ that constitute the shortest path from node $s$ to node $t$ in $\tilde{G}$ $\mathcal{P}:=\varnothing$

forall $(i, j) \in \tilde{\mathcal{P}}$

| Let $\mathcal{P}_{(i, j)}$ be the set of arcs in the original graph $G$ that lies on the shortest path from node $i$ to node $j$.

$\mathcal{P}=\mathcal{P} \cup \mathcal{P}_{(i, j)}$.

\section{end}

Solve the MCPP formulation for the path $\mathcal{P}$.

\section{end}

\section{References}

Albertus, P., Couts, J., Srinivasan, V., Newman, J., 2008. II. A combined model for determining capacity usage and battery size for hybrid and plug-in hybrid electric vehicles. J. Power Sources 183, 771-782.

Arslan, O., Karașan, O.E., 2013. Cost and emission impacts of virtual power plant formation in plug-in hybrid electric vehicle penetrated networks. Energy 60, $116-124$.

Arslan, O., Yıldız, B., Karaşan, O.E., 2014. Minimum cost path problem for plug-in hybrid electric vehicles, in preparation. 〈www.optimization-online.org/ DB_HTML/2014/02/4230.html).

Axsen, J., Kurani, K.S., 2013. Hybrid, plug-in hybrid, or electric-what do car buyers want? Energy Policy 61, 532-543.

Axsen, J., Kurani, K.S., McCarthy, R., Yang, C., 2011. Plug-in hybrid vehicle GHG impacts in California: integrating consumer-informed recharge profiles with an electricity-dispatch model. Energy Policy 39, 1617-1629.

Catenacci, M., Verdolini, E. Bosetti, V., Fiorese, G, 2013. Going electric: expert survey on the future of battery technologies for electric vehicles. Energy Policy 61, 403-413.

Davies, J., Kurani, K.S., 2013. Moving from assumption to observation: Implications for energy and emissions impacts of plug-in hybrid electric vehicles. Energy Policy 62, 550-560.

Electric Power Research Institute, 2005. Batteries for Electric Drive Vehicles Status 2005. Technical Report. Electric Power Research Institute.

Eppstein, M.J., Grover, D.K., Marshall, J.S., Rizzo, D.M., 2011. An agent-based model to study market penetration of plug-in hybrid electric vehicles. Energy Policy 39, 3789-3802.

Franke, T., Krems, J.F., 2013. What drives range preferences in electric vehicle users? Transp. Policy 30, 56-62.

Galus, M.D., Zima, M., Andersson, G., 2010. On integration of plug-in hybrid electric vehicles into existing power system structures. Energy Policy 38, 6736-6745.

Gardner, L.M., Duell, M., Waller, S.T., 2013. A framework for evaluating the role of electric vehicles in transportation network infrastructure under travel demand variability. Transp. Res. Part A: Policy Pract. 49, 76-90.

He, F., Wu, D., Yin, Y., Guan, Y., 2013. Optimal deployment of public charging stations for plug-in hybrid electric vehicles. Transp. Res. Part B: Methodol. 47, 87-101.

Karabasoglu, O., Michalek, J., 2013. Influence of driving patterns on life cycle cost and emissions of hybrid and plug-in electric vehicle powertrains. Energy Policy 60, 445-461.

Khan, M., Kockelman, K.M., 2012. Predicting the market potential of plug-in electric vehicles using multiday GPS data. Energy Policy 46, 225-233.

Khan, S.A., Kushler, M., 2013. Plug-in Electric Vehicles: Challenges and Opportunities. URL: 〈http://community-wealth.org/files/downloads/report-kahn-kush ler.pdf $\rangle$ (accessed 18.05.14).

Kutner, M.H., Nachtsheim, C.J., Neter, J., Li, W., 2005. Applied Linear Statistical Models, vol. 6. McGraw-Hill, New York.

Kyle, P., Kim, S.H., 2011. Long-term implications of alternative light-duty vehicle technologies for global greenhouse gas emissions and primary energy demands. Energy Policy 39, 3012-3024.

Li, F., Cheng, D., Hadjieleftheriou, M., Kollios, G., Teng, S.H., 2005. On trip planning queries in spatial databases. In: Advances in Spatial and Temporal Databases. Springer, Berlin, Heidelberg, pp. 273-290.

Lunz, B., Yan, Z., Gerschler, J.B., Sauer, D.U., 2012. Influence of plug-in hybrid electric vehicle charging strategies on charging and battery degradation costs. Energy Policy 46, 511-519.

Ma, H., Balthasar, F., Tait, N., Riera-Palou, X., Harrison, A., 2012. A new comparison between the life cycle greenhouse gas emissions of battery electric vehicles and internal combustion vehicles. Energy Policy 44, 160-173.

Marshall, B.M., Kelly, J.C., Lee, T.K., Keoleian, G.A., Filipi, Z., 2013. Environmental assessment of plug-in hybrid electric vehicles using naturalistic drive cycles and vehicle travel patterns: Michigan case study. Energy Policy 58, 358-370.

Millner, A., 2010. Modeling lithium ion battery degradation in electric vehicles, Innovative Technologies for an Efficient and Reliable Electricity Supply (CITRES), 2010 IEEE Conference on IEEE, 349-356.

MirHassani, S., Ebrazi, R., 2012. A flexible reformulation of the refueling station location problem. Transp. Sci. 47, 617-628.

Neubauer, J., Brooker, A., Wood, E., 2013. Sensitivity of plug-in hybrid electric vehicle economics to drive patterns, electric range, energy management, and charge strategies. J. Power Sources 236, 357-364.

Neubauer, J., Pesaran, A., 2011. The ability of battery second use strategies to impact plug-in electric vehicle prices and serve utility energy storage applications. J. Power Sources 196, 10351-10358. 
Neubauer, J., Pesaran, A., 2013. A Techno-Economic Analysis of BEV Service Providers Offering Battery Swapping Services. National Renewable Energy Laboratory.

Nurre, S.G., Bent, R., Pan, F., Sharkey, T.C., 2014. Managing operations of plug-in hybrid electric vehicle (phev) exchange stations for use with a smart grid. Energy Policy 67, 364-377.

Özdemir, Enver Doruk, Hartmann, Niklas, 2012. Impact of electric range and fossil fuel price level on the economics of plug-in hybrid vehicles and greenhouse gas abatement costs. Energy Policy 46, 185-192.

Pearre, N.S., Kempton, W., Guensler, R.L., Elango, V.V., 2011. Electric vehicles: how much range is required for a days driving?. Transp. Res. Part C: Emerg. Technol. $19,1171-1184$

Perk, V.A., DeSalvo, J.S., Rodrigues, T.A., Versoza, N.M., Bovino, S.C., 2011. Improving Value of Travel Time Savings Estimation for More Effective Transportation Project Evaluation.

Peterson, S.B., Apt, J., Whitacre, J., 2010. Lithium-ion battery cell degradation resulting from realistic vehicle and vehicle-to-grid utilization. J. Power Sources 195, 2385-2392.

Peterson, S.B., Michalek, J.J., 2013. Cost-effectiveness of plug-in hybrid electric vehicle battery capacity and charging infrastructure investment for reducing US gasoline consumption. Energy Policy 52, 429-438.

Romm, J., 2006. The car and fuel of the future. Energy Policy 34, 2609-2614.

Scrosati, B., Garche, J., 2010. Lithium batteries: status, prospects and future. J. Power Sources 195, 2419-2430.

Shiau, C.S.N., Samaras, C., Hauffe, R., Michalek, J.J., 2009. Impact of battery weight and charging patterns on the economic and environmental benefits of plug-in hybrid vehicles. Energy Policy 37, 2653-2663.
Sioshansi, R., Denholm, P., 2010. The value of plug-in hybrid electric vehicles as grid resources. Energy J. 31, 1-24.

Sioshansi, R., Miller, J., 2011. Plug-in hybrid electric vehicles can be clean and economical in dirty power systems. Energy Policy 39, 6151-6161.

Smith, W.J., 2010. Plug-in hybrid electric vehicles a low-carbon solution for Ireland? Energy Policy 38, 1485-1499.

Stephan, C.H., Sullivan, J., 2008. Environmental and energy implications of plug-in hybrid-electric vehicles. Environ. Sci. Technol. 42, 1185-1190.

Tesla Motors, 2014. Superchargers. 〈http://www.teslamotors.com/supercharger〉.

United States Department of Transportation, 2010. National Household Trave Survey. URL: 〈http://nhts.ornl.gov/det/Extraction3.aspx〉 (accessed 16.02.14).

US Census Bureau, 2010. Urban, Urbanized Area, Urban Cluster, and Rural Population, 2010 and 2000: United States. URL: 〈http://www.census.gov/geo/refer ence/ua/urban-rural-2010.html (accessed 18.05.14).

US Energy Information Administration, 2014a. Average Retail Prices of Electricity. URL: 〈http://www.eia.gov/totalenergy/data/monthly/pdf/sec9_11.pdf〉 (accessed 18.05.14)

U.S. Energy Information Administration, 2014b. Weekly Retail Gasoline and Diesel Prices. URL: 〈http://www.eia.gov/dnav/pet/pet_pri_gnd_dcus_nus_w.htm〉 (accessed May 18.05.14).

Wang, Y.W., Lin, C.C., 2009. Locating road-vehicle refueling stations. Transp. Res. Part E: Logist. Transp. Rev. 45, 821-829.

Weiller, C., 2011. Plug-in hybrid electric vehicle impacts on hourly electricity demand in the united states. Energy Policy 39, 3766-3778. 